\title{
CORRIGENDA
}

\section{Life events moderate variation in cognitive ability $(g)$ in adults}

\author{
AAE Vinkhuyzen, $S$ van der Sluis and D Posthuma \\ Molecular Psychiatry (2010) 15, 1197; doi:10.1038/mp.2010.32; published online 7 September 2010
}

Correction to: Molecular Psychiatry advance online publication, 16 February 2010; doi:10.1038/mp.2010.12

The affiliations were incorrect. The correct affiliations list appears below:

AAE Vinkhuyzen ${ }^{1,2}$, S van der Sluis ${ }^{1}$ and D Posthuma ${ }^{1,3}$
${ }^{1}$ Section Functional Genomics, Center for Neurogenomics and Cognitive Research (CNCR), VU University Amsterdam, Amsterdam, The Netherlands; ${ }^{2}$ Department of Biological Psychology, VU University Amsterdam, Amsterdam, The Netherlands and ${ }^{3}$ Section Medical Genomics, VU Medical Centre, Amsterdam, The Netherlands

\section{Social network determinants of depression}

JN Rosenquist, JH Fowler and NA Christakis

Molecular Psychiatry (2010) 15, 1197; doi:10.1038/mp.2010.48

Correction to: Molecular Psychiatry advance online publication, 16 March 2010; doi:10.1038/mp.2010.13

Since the online publication of the above paper, the authors noticed that the following text was missing in the Acknowledgements:

This work was supported by an NIH grant (P01 AG31093) from the National Institute on Aging and by a grant from the Pioneer Portfolio of the Robert Wood Johnson Foundation.
The complete Acknowledgements is as below:

This work was supported by an NIH grant (P01 AG31093) from the National Institute on Aging and by a grant from the Pioneer Portfolio of the Robert Wood Johnson Foundation. We thank Laurie Meneades, Rebecca Joyce, Molly Collins, Marian Bellwood and Karen Mutalik for the expert assistance given to build the analytical data. We thank Maurizio Fava for helpful comments regarding the article. 